\title{
Effects of Chronic Administration and Withdrawal of Antidepressant Agents on Circadian Activity Rhythms in Rats
}

\author{
FRANZISKA WOLLNIK \\ Department of Biology, University of Konstanz, P.O. Box 5560, D-7750 Konstanz, Germany
}

Received 10 December 1991

\begin{abstract}
WOLLNIK, F. Effects of chronic administration and withdrawal of antidepressant agents on circadian activity rhythms in rats. PHARMACOL BIOCHEM BEHAV 43(2) 549-561, 1992. - Experimental and clinical studies indicate that clinical depression may be associated with disturbances of circadian rhythms. To explore the interaction between circadian rhythmicity, behavioral state, and monoaminergic systems, the present study investigated the effects of chronic administration and withdrawal of the following antidepressant agents on circadian wheel-running rhythms of laboratory rats: a) moclobemide, a reversible and selective monoamine oxidase (MAO) type A inhibitor; b) Ro 19-6327, a selective MAO type B inhibitor; c) desipramine, a preferential norepinephrine reuptake inhibitor; d) clomipramine and e) fluoxetine, both serotonin reuptake inhibitors; and f) levoprotiline, an atypical antidepressant whose biochemical mechanism is still unknown. Wheel-running activity rhythms were studied in three inbred strains of laboratory rats (ACI, BH, LEW) under constant darkness (DD). Two of these inbred strains (BH and LEW) show profound abnormalities in their circadian activity rhythms, namely, a reduced overall level of activity and bimodal or multimodal activity patterns. Chronic treatment with moclobemide and desipramine consistently increased the overall level, as well as the circadian amplitude, of the activity rhythm. Furthermore, the abnormal activity pattern of the LEW strain was changed into a unimodal activity pattern like that of other laboratory rats. The free-running period $\tau$ was slightly shortened by moclobemide and dramatically shortened by desipramine. Effects of moclobemide and desipramine treatment on overall activity level and duration were reversed shortly after termination of treatment, whereas long aftereffects were observed for the free-running period. All other substances tested had no systematic effects on the activity rhythms of any of the strains. The fact that moclobemide and desipramine altered the period, amplitude, and pattern of circadian activity rhythms is consistent with the hypothesis that monoaminergic transmitters play a significant role in the neuronal control of behavioral state and circadian rhythmicity. Although the present study found that some antidepressives affect parameters of circadian rhythmicity, it could not demonstrate a common effect of all classes of antidepressives.
\end{abstract}

Circadian rhythms Genetic differences Inbred strains Antidepressives Moclobemide Ro 19-6327

Desipramine Clomipramine Fluoxetine Levoprotiline

IT has often been suggested that there is an association between the pathophysiology of affective disorders and disturbances of circadian rhythms. For example, studies in humans have shown that affective disorders are associated with abnormalities in the period, phase, and/or amplitude of physiologi$\mathrm{cal}$, behavioral, and endocrine rhythms, resulting in quite a number of different hypotheses on the chronobiology of depression $(16,18,20,39,41)$. Special attention has been paid to the observation that many circadian rhythms, including the circadian rhythm of rapid eye movement (REM) sleep and deep body temperature, are phase advanced in depressed patients compared to controls $(12,27,42,43)$.

According to the current knowledge about how circadian rhythms are generated and entrained (28), an abnormally advanced phase position of circadian rhythms could result from: a) an abnormally short period $\tau$ of the underlying circadian pacemaker; b) an abnormal phase coupling between the intrinsic pacemaker and entraining signals such as the light-dark cycle; and c) an abnormal phase coupling between the circadian pacemaker and overt behavioral and physiological rhythms.

In this context, it is of special significance that various antidepressant drugs can slow and delay circadian rhythms in animals [for reviews, see $(8,43)$ ]. Lithium, the first and most extensively studied psychoactive drug, lengthens the freerunning rhythm and delays the phase position in a variety of species, including marine algae, higher plants, insects, mammals, and humans [for summaries, see $(8,43,44)$ ]. Other antidepressant drugs that lengthen or phase delay circadian rhythms in mammals are clorgyline $(7,25,37,45)$, a monoamine oxidase (MAO) type $A$ inhibitor, pargyline $(30,42)$, a mixed MAO type A and B inhibitor, and imipramine $(13,25,43)$, a tricyclic monoamine reuptake inhibitor. However, the period-lengthening effect of imipramine seems less robust than that of clorgyline $(2,8,36,45)$. In general, results of these and other studies have been interpreted to the effect 
TABLE 1

EFFECT OF CHRONIC DRUG TREATMENT (DAYS 15-28) ON BODY WEIGHT AND FOOD CONSUMPTION OF THE THREE INBRED STRAINS. ACl, BH, AND LEW

\begin{tabular}{|c|c|c|c|c|c|c|c|c|c|c|c|c|}
\hline \multirow[b]{3}{*}{ Anımals } & \multicolumn{12}{|c|}{ Body weight (g) } \\
\hline & \multicolumn{2}{|l|}{ Moclobemide } & \multicolumn{2}{|l|}{ Ro $19-6327$} & \multicolumn{2}{|l|}{ Desipramine } & \multicolumn{2}{|l|}{ Clomipramine } & \multicolumn{2}{|l|}{ Fluoxetıne } & \multicolumn{2}{|l|}{ Levoprotiline } \\
\hline & Mean $\pm S E$ & $n$ & Mean \pm SE & $n$ & Mean $\pm \mathrm{SE}$ & $n$ & Mean $\pm \mathrm{SE}$ & $n$ & Mean $\pm \mathrm{SE}$ & $n$ & Mean $\pm \mathrm{SE}$ & $n$ \\
\hline \multicolumn{13}{|l|}{$\mathrm{ACI}$} \\
\hline Day 1 & $152 \pm 4.2$ & 6 & $201 \pm 4.7$ & 5 & $190 \pm 2.87$ & 6 & $214 \pm 3.6$ & 5 & $185 \pm 14.9$ & 6 & $184 \pm 8.6$ & 6 \\
\hline Day 15 & $171 \pm 3.47$ & 6 & $234 \pm 6.37$ & 5 & $199 \pm 9.3-$ & 6 & $231 \pm 2.9$ & 5 & $194 \pm 13.87$ & 5 & $207 \pm 4.37$ & 6 \\
\hline Day 29 & $179 \pm 4.6]$ & 6 & $228 \pm 7.2-$ & 5 & $192 \pm 5.6$ & 6 & $230 \pm 6.2]$ & 5 & $201 \pm 5.0\rfloor$ & 5 & $220 \pm 5.0-$ & 5 \\
\hline Day 42 & $215 \pm 3.7$ & 6 & $230 \pm 11.8]$ & 5 & $195 \pm 5.8$ & 6 & $240 \pm 8.8$ & 5 & $235 \pm 5.8$ & 5 & $214 \pm 6.2]$ & 5 \\
\hline \multicolumn{13}{|l|}{$\mathrm{BH}$} \\
\hline Day 1 & $176 \pm 2.3$ & 6 & $240 \pm 5.5$ & 6 & $131 \pm 6.3$ & 6 & $195 \pm 10.8$ & 5 & $229 \pm 9.0$ & 6 & $262 \pm 13.7$ & \\
\hline Day 15 & $254 \pm 6.27$ & 6 & $256 \pm 5.97$ & 6 & $213 \pm 11.37$ & 6 & $215 \pm 18.37$ & 5 & $279 \pm 16.7]$ & 6 & $316 \pm 6.5$ & 6 \\
\hline Day 29 & $263 \pm 7.8$ & 6 & $263 \pm 14.7\rfloor$ & 6 & $226 \pm 8.3\rfloor$ & 6 & $222 \pm 6.5$ & 5 & $282 \pm 8.1-$ & 6 & $331 \pm 8.6$ & 5 \\
\hline Day 42 & $295 \pm 10.8$ & 6 & $296 \pm 12.8$ & 6 & $250 \pm 7.9$ & 6 & $257 \pm 8.5$ & 5 & $293 \pm 6.4 \mathrm{~J}$ & 6 & $345 \pm 8.4$ & 5 \\
\hline \multicolumn{13}{|l|}{ LEW } \\
\hline Day 1 & $205 \pm 7.4$ & 6 & $250 \pm 5.1$ & 6 & $224 \pm 14.5$ & 6 & $277 \pm 6.7$ & 6 & $232 \pm 9.2$ & 6 & $276 \pm 2.5$ & 5 \\
\hline Day 15 & $250 \pm 7.27$ & 6 & $260 \pm 10.27$ & 6 & $293 \pm 19.57$ & 6 & $308 \pm 16.87$ & 6 & $247 \pm 11.07$ & 6 & $296 \pm 10.37$ & 5 \\
\hline Day 29 & $244 \pm 5.5]$ & 6 & $259 \pm 10.8]$ & 6 & $292 \pm 13.6^{\rfloor}$ & 6 & $304 \pm 13.5$ & 6 & $246 \pm 9.2-$ & 6 & $304 \pm 10.5-$ & 5 \\
\hline Day 42 & $277 \pm 6.7$ & 6 & $277 \pm 9.3$ & 6 & $326 \pm 14.6$ & 6 & $331 \pm 11.3$ & 6 & $255 \pm 11.7\rfloor$ & 6 & $317 \pm 8.2$ & 5 \\
\hline \multirow{5}{*}{$\begin{array}{l}F_{\text {Strains }} \\
F_{\text {Days }} \\
F_{\text {Interactions }}\end{array}$} & \multicolumn{2}{|c|}{$(2,60)=147.6^{*}$} & \multicolumn{2}{|l|}{$(2,56) 130.6^{*}$} & \multicolumn{2}{|l|}{$(2,60) 1.85^{*}$} & \multicolumn{2}{|l|}{$(2,52) 79.4^{*}$} & \multicolumn{2}{|l|}{$(2,57) 175.6^{*}$} & \multirow{3}{*}{\multicolumn{2}{|c|}{$\begin{array}{c}(2,54) 205.4^{*} \\
(3,54) 16.9^{*} \\
(6,54) 3.8^{*}\end{array}$}} \\
\hline & $(3,60)=82$. & & $(3,56) 5.5^{*}$ & & $(3,60) 6.8^{*}$ & & $(3,52) 10.7^{*}$ & & $(3,57) 9.1^{*}$ & & & \\
\hline & $(6,60)=6.9$ & & $(6,56) 3.1^{*}$ & & $(6,60) 3.4^{*}$ & & $(6,52) 3.0^{*}$ & & $(6,57) 3.5^{*}$ & & & \\
\hline & \multicolumn{12}{|c|}{ Food consumption ( $\mathrm{g} / 100 \mathrm{~g} \mathrm{BW})$} \\
\hline & Moclobemide & & Ro $19-6327$ & & Desıpramine & & Clomipramine & & Fluoxetıne & & Levoprotiline & \\
\hline Animals & Mean $\pm \mathrm{SE}$ & $n$ & Mean $\pm \mathrm{SE}$ & $n$ & Mean $\pm \mathrm{SE}$ & $n$ & Mean $\pm \mathrm{SE}$ & $n$ & Mean $\pm \mathrm{SE}$ & $n$ & Mean $\pm \mathrm{SE}$ & $n$ \\
\hline ACI & & & & & & & & & & & & \\
\hline Day $1-7$ & $75.2 \pm 3.9$ & 6 & $52.4 \pm 4.5$ & 5 & $80.3 \pm 1.8$ & 6 & $64.0 \pm 2.5$ & 5 & $69.5 \pm 5.4$ & 6 & $72.3 \pm 7.0$ & 6 \\
\hline Day $8-14$ & $71.0 \pm 3.4$ & 6 & $59.7 \pm 2.2$ & 5 & $67.2 \pm 4.2$ & 6 & $65.1 \pm 2.0$ & 5 & $64.1 \pm 2.5$ & 6 & $64.9 \pm 3.8$ & 6 \\
\hline Day $15-21$ & $65.2 \pm 4.3$ & 6 & $63.9 \pm 2.9$ & 5 & $43.9 \pm 4.3$ & 6 & $38.6 \pm 3.6$ & 5 & $59.0 \pm 4.7$ & 5 & $68.0 \pm 4.6$ & 6 \\
\hline Day $22-28$ & $63.7 \pm 1.1$ & 6 & $62.3 \pm 2.1$ & 5 & $55.3 \pm 1.9$ & 6 & $49.0 \pm 2.1$ & 5 & $46.6 \pm 2.5$ & 5 & $62.5 \pm 3.9$ & 6 \\
\hline Day 29-35 & $70.5 \pm 1.9$ & 6 & $66.4 \pm 5.5$ & 5 & $66.0 \pm 2.7$ & 6 & $58.0 \pm 2.5$ & 5 & $71.2 \pm 2.2$ & 5 & $62.5 \pm 4.1$ & 5 \\
\hline Day 36-42 & $62.9 \pm 2.0$ & 6 & $52.3 \pm 3.1$ & 5 & $40.6 \pm 4.4$ & 6 & $42.5 \pm 2.3$ & 5 & $57.9 \pm 2.3$ & 5 & $56.3 \pm 6.6$ & 5 \\
\hline $\mathrm{BH}$ & & & & & & & & & & & & \\
\hline Day 1-7 & $72.7 \pm 4.3$ & 6 & $32.6 \pm 6.8$ & 6 & $68.7 \pm 2.6$ & 6 & $46.5 \pm 5.1$ & 5 & $64.6 \pm 2.2$ & 6 & $61.6 \pm 4.9$ & 6 \\
\hline Day $8-14$ & $64.1 \pm 1.3$ & 6 & $39.6 \pm 5.2$ & 6 & $68.5 \pm 2.1$ & 6 & $65.4 \pm 4.2$ & 5 & $51.0 \pm 1.7$ & 6 & $48.9 \pm 1.0$ & 6 \\
\hline Day 15-21 & $60.8 \pm 1.1$ & 6 & $58.0 \pm 5.7$ & 6 & $50.5 \pm 1.6$ & 6 & $54.2 \pm 5.6$ & 5 & $53.1 \pm 5.6$ & 6 & $53.8 \pm 3.3$ & 6 \\
\hline Day $22-28$ & $54.2 \pm 1.3$ & 6 & $45.2 \pm 3.5$ & 6 & $56.1 \pm 1.4$ & 6 & $46.9 \pm 1.0$ & 5 & $37.6 \pm 3.6$ & 6 & $44.8 \pm 1.0$ & 6 \\
\hline Day 29-35 & $67.2 \pm 4.9$ & 6 & $48.7 \pm 5.2$ & 6 & $59.1 \pm 3.2$ & 6 & $53.7 \pm 5.8$ & 5 & $41.5 \pm 7.7$ & 6 & $46.9 \pm 3.9$ & 5 \\
\hline Day 36-42 & $53.8 \pm 2.5$ & 6 & $46.9 \pm 6.2$ & 6 & $59.9 \pm 3.0$ & 6 & $47.8 \pm 2.3$ & 5 & $48.0 \pm 4.8$ & 6 & $47.8 \pm 2.2$ & 5 \\
\hline LEW & & & & & & & & & & & & \\
\hline Day 1-7 & $68.0 \pm 1.2$ & 6 & $38.6 \pm 4.0$ & 6 & $69.5 \pm 7.9$ & 6 & $55.3 \pm 3.6$ & 6 & $44.0 \pm 2.3$ & 6 & $48.3 \pm 3.4$ & 5 \\
\hline Day $8-14$ & $65.4 \pm 1.3$ & 6 & $42.8 \pm 2.5$ & 6 & $57.6 \pm 8.4$ & 6 & $52.8 \pm 5.7$ & 6 & $38.7 \pm 2.6$ & 6 & $48.0 \pm 3.3$ & 5 \\
\hline Day $15-21$ & $53.4 \pm 2.0$ & 6 & $45.9 \pm 2.6$ & 6 & $41.0 \pm 6.0$ & 6 & $32.6 \pm 2.6$ & 6 & $38.9 \pm 1.4$ & 6 & $55.8 \pm 5.4$ & 5 \\
\hline Day $22-28$ & $56.8 \pm 1.6$ & 6 & $36.5 \pm 1.6$ & 6 & $49.4 \pm 7.2$ & 6 & $41.9 \pm 2.2$ & 6 & $31.0 \pm 1.0$ & 6 & $43.7 \pm 4.7$ & 5 \\
\hline Day 29-35 & $58.7 \pm 1.9$ & 6 & $46.6 \pm 1.9$ & 6 & $55.4 \pm 5.5$ & 6 & $48.0 \pm 2.6$ & 6 & $46.0 \pm 2.1$ & 6 & $54.1 \pm 3.7$ & 5 \\
\hline Day 36-42 & $58.4 \pm 2.4$ & 6 & $40.5 \pm 4.0$ & 6 & $54.4 \pm 7.7$ & 6 & $40.2 \pm 1.7$ & 6 & $35.4 \pm 2.5$ & 6 & $40.8 \pm 4.1$ & 5 \\
\hline$F_{\text {Strans }}$ & $(2,90)=14$. & & $(2,84) 36.6^{*}$ & & $(2,90) 4.9^{*}$ & & $(2,78) 9.2^{*}$ & & $(2,88) 57.8^{*}$ & & $(2,80) 25.3^{*}$ & \\
\hline$F_{\text {Days }}$ & $(5,90)=34$ & & $(5,84) 3.8 \dagger$ & & $(5,90) 26.5^{*}$ & & $(5,78) 14.0^{*}$ & & $(5,88) 11.1^{*}$ & & $(5,80) 3.9^{*}$ & \\
\hline$F_{\text {Interactions }}$ & $(10,90)=2$ & & $(10,84) 2.2 \dagger$ & & $(10,90) 2.5^{*}$ & & $(10,78) 3.1^{*}$ & & $(10,88) 2.2 \dagger$ & & $(10,80) 2.9^{*}$ & \\
\hline
\end{tabular}

*Differences between strains, pharmacological treatments, and strain-treatment interactions were assessed using standard procedures of ANOVA (two-way ANOVA for repeated measurements). Brackets indicate body weight values that were not significantly different from each other.

${ }^{*} p \leq 0.01$.

$\dagger p \leq 0.05$. 
TABLE 2

AVERAGE UPTAKE RATES OF ANTIDEPRESSANT AGENTS FOR ACl, BH AND LEW RATS

\begin{tabular}{lccc}
\hline & \multicolumn{3}{c}{ Daily Drug Intake (mg/kg body weight) } \\
\cline { 2 - 4 } & $\mathrm{ACl}$ & $\mathrm{BH}$ & LEW \\
\hline Moclobemide & 28 & 27 & 25 \\
Ro 19-6327 & 3.6 & 3 & 2.4 \\
Desipramine & 32 & 34 & 29 \\
Clomipramine & 23 & 27 & 23 \\
Fluoxetine & 11 & 10 & 8 \\
Levoprotiline & 43 & 32 & 32 \\
\hline
\end{tabular}

that these drugs slow the mammalian circadian pacemaker. However, some studies reported additional effects such as dissociation (45) and splitting (19) of circadian rhythms, while others found no effect of antidepressant drugs on the circadian period at all $(2,29,36)$.

It should be noted that almost all these investigations examined the effects of psychoactive drugs on animals such as golden hamsters or laboratory rats that have "normal" circadian rhythms rather than "abnormal" rhythms that might be more representative of clinical depression. To my knowledge, there is only one study that demonstrates how chronic antidepressant administration can reestablish a normal phase position in animals with a phase-advanced activity rhythm caused by complete social isolation (13).

To account for this deficiency, this study used two commonly available inbred strains, $\mathrm{BH}$ and LEW, of laboratory rats with genetically fixed differences in circadian rhythm parameters (46-48). These strains have rather unusual activity patterns that may be caused by multiple circadian oscillators coupled to each other with a phase relationship of 4-6 h $(34,46-48)$. The goal of the study was to investigate the effects of various antidepressant drugs on the circadian wheelrunning rhythms of the two strains compared to strain ACI, which shows an activity pattern found in most laboratory rats. In a chronic drug administration protocol, the major types of drugs used to treat affective disorders were tested: a) moclobemide, a reversible and highly selective type A MAO inhibitor $(4,5)$; b) Ro 19-6327, a selective type B MAO inhibitor (14); c) desipramine, a tricyclic preferential norepinephrine reuptake inhibitor $(17,21)$; d) clomipramine, a tricyclic preferential serotonin reuptake inhibitor (49); e) fluoxetine, a nontricyclic selective serotonin reuptake inhibitor $(11,17,49)$; and $f$ ) levoprotiline, the (-)-enantiomer of oxaprotiline with an unknown biochemical mechanism $(6,21)$.

\section{METHOD}

\section{Animals and Housing}

Male rats of the inbred strains $\mathrm{ACI} / \mathrm{Ztm}$ (agouti), $\mathrm{BH} /$ Ztm (black hooded), and LEW/Ztm (albino), originally obtained from the central animal laboratory at the Hanover Medical School (Germany), were bred and raised in our laboratory under controlled environmental conditions (12 L : $12 \mathrm{D}$ cycle, lights on at $0700 \mathrm{~h}$, room temperature $22 \pm 1^{\circ} \mathrm{C}$ ). For each experiment six littermates of each strain, 10-12 weeks old, were singly housed in cages (Makrolon [Becker, CastropRaùxel, Germany] Type IV, $35 \times 55 \times 10 \mathrm{~cm}$ ) equipped with a running wheel (diameter $35 \mathrm{~cm}$, width $10 \mathrm{~cm}$ ). Groups of four running wheel cages each were housed within ventilated, light-tight, stainless steel compartments. Wheel-running activity was monitored under constant dark conditions (DD) for 6-8 weeks. Animals had free access to the running wheel; food and water were supplied ad lib. Animals were checked once per week at irregular times during their subjective night, that is, during their active phase, using an infrared light viewer (FJW Optical Systems, Inc., Palatine, IL). At these occasions, remaining food was weighed, food and water were replenished, and cages were changed if necessary.

\section{Data Collection and Analysis}

Three magnetic reed switches were mounted on each running wheel axle so that one complete wheel revolution resulted in three impulses. The number of impulses per 5-min interval was recorded continuously by a microcomputer (Apple II +). All subsequent calculations were based on these 5-min counts.

Periods $\tau$ of the free-running circadian rhythm were estimated using the $\chi^{2}$ periodogram (35). Harmonic spectral analysis $(15,26)$ was used to verify the presence of characteristic frequencies in the data. Further details of the statistical models underlying these two approaches are described elsewhere $(46,47)$.

Additional parameters calculated from the activity recordings include: a) overall level of activity, defined as total number of counts over a 24-h period given in impulses/day; b) duration of wheel-running activity, defined as total length of all 5 -min intervals within $24 \mathrm{~h}$ containing more than 5 impulses given in $\mathrm{min} /$ day. In all experiments, differences between strains and pharmacological treatments were evaluated by two-way analyses of variance (ANOVAs) for repeated measurements, followed by Tukey's multiple $t$-test for individual mean comparisons. Pearson's $r$ was used for expressing correlations.

\section{Procedures}

Separate experiments were conducted for each of the six substances. In each experiment, five to six animals of each strain were recorded. After 14 days of free-running baseline conditions, the following antidepressant agents were administered for 14 days: moclobemide, Ro 19-6327, desipramine, clomipramine (all supplied by F. Hoffman-La Roche Ltd., Basel, Switzerland), fluoxetine (supplied by Lilly, Indianapolis, IN), and levoprotiline (supplied by CIBA-GEIGY Ltd., Basel, Switzerland). After 14 days, drug treatment was terminated and the recording was continued for 2 more weeks with normal food. The antidepressants were administered ad lib in food mixtures prepared by KLIWA. The mixtures were identi$\mathrm{cal}$ to the standard powdered diet used during baseline and withdrawal conditions except they contained the following concentrations of antidepressants per kg food: moclobemide, $300 \mathrm{mg} / \mathrm{kg}$; Ro 19-6327, $40 \mathrm{mg} / \mathrm{kg}$; desipramine, $375 \mathrm{mg} / \mathrm{kg}$; clomipramine, $450 \mathrm{mg} / \mathrm{kg}$; fluoxetine, $152 \mathrm{mg} / \mathrm{kg}$; levoprotiline, $450 \mathrm{mg} / \mathrm{kg}$. Assuming a daily food intake of approximately $20 \mathrm{~g}$ for a rat of $300 \mathrm{~g}$ body weight, these food mixtures produced an average daily drug intake per $\mathrm{kg}$ body weight of $20 \mathrm{mg}$ moclobemide, $2.5 \mathrm{mg}$ Ro 19-6327, $25 \mathrm{mg}$ desipramine, $30 \mathrm{mg}$ clomipramine, $10 \mathrm{mg}$ fluoxetine, and $30 \mathrm{mg}$ levoprotiline. These doses had been found to be most effective for chronical treatment of rats (personal communications with $\mathrm{F}$. Hoffman-La Roche Ltd., Lilly, and CIBA-GEIGY Ltd.). The powdered food was provided in a glass jar braced against the cage with a wire spring. Food intake was measured every week and body weight every 2 weeks during the regular checks of 

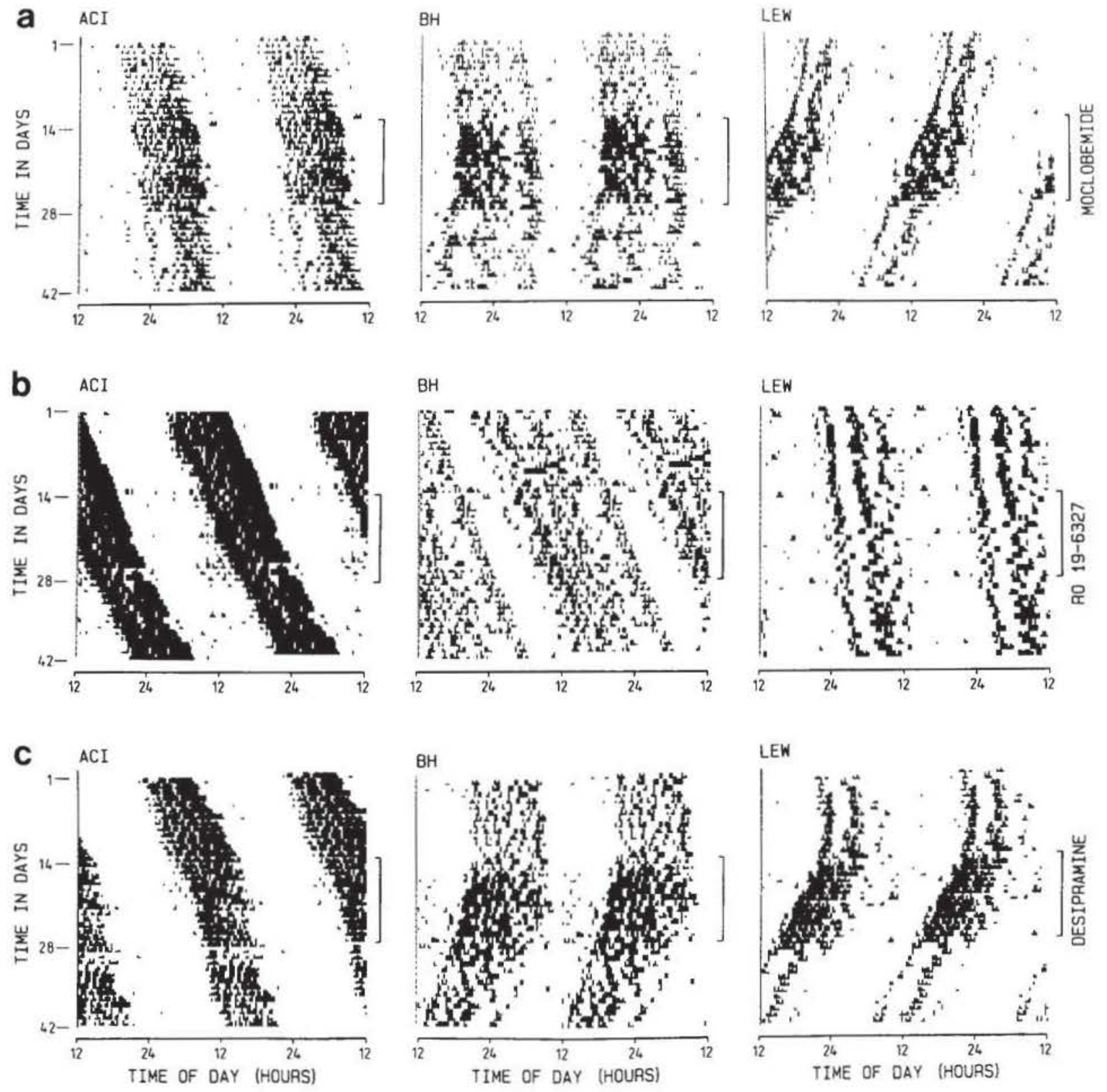

FIG. 1. Characteristic recordings of wheel-running activity from $\mathrm{ACl}, \mathrm{BH}$, and $\mathrm{LEW}$ rats. Following 14 days of baseline conditions, anımals wre chronically treated with moclobemide (a), Ro 19-6327/001 (b), desıpramine (c), clomipramine (d), fluoxetıne (e), or levoprotiline (f). Numbers on the vertical axes denote days of experiment; numbers on the horizontal axes denote daytime hours. Activity records are shown as doule plots to facilitate visualization of free-running rhythms. Each 48-h period consists of 144 bins, where the height of each bin represents the number of impulses during a 20 -min interval (20-200 impulses/bin).

animals. Statistical parameters of the wheel-running rhythms were computed for each of the following three conditions: baseline (days 1-14), drug treatment (days 15-28), and drug withdrawal (days 29-42).

\section{RESULTS}

\section{Body Weight and Food Consumption}

Measurements of body weight and food consumption are summarized in Table 1. Repeated-measures ANOVA indicated significant differences between body weights of the three strains, with animals of the ACI strain being generally lighter than animals of the BH and LEW strains. In all six experiments, drug treatment (days 14-28) caused a temporary halt in the otherwise continuous increase in body weight, and sometimes even a decrease, for example, in the ACI strain under Ro 19-6327, desipramine, and clomipramine treatment. However, these effects were minor and did not affect the health or well-being of animals.

Due to the strain differences in body weight, measurements of food intake were expressed with respect to body weight. As could be expected from the interruption in body weight gain, 

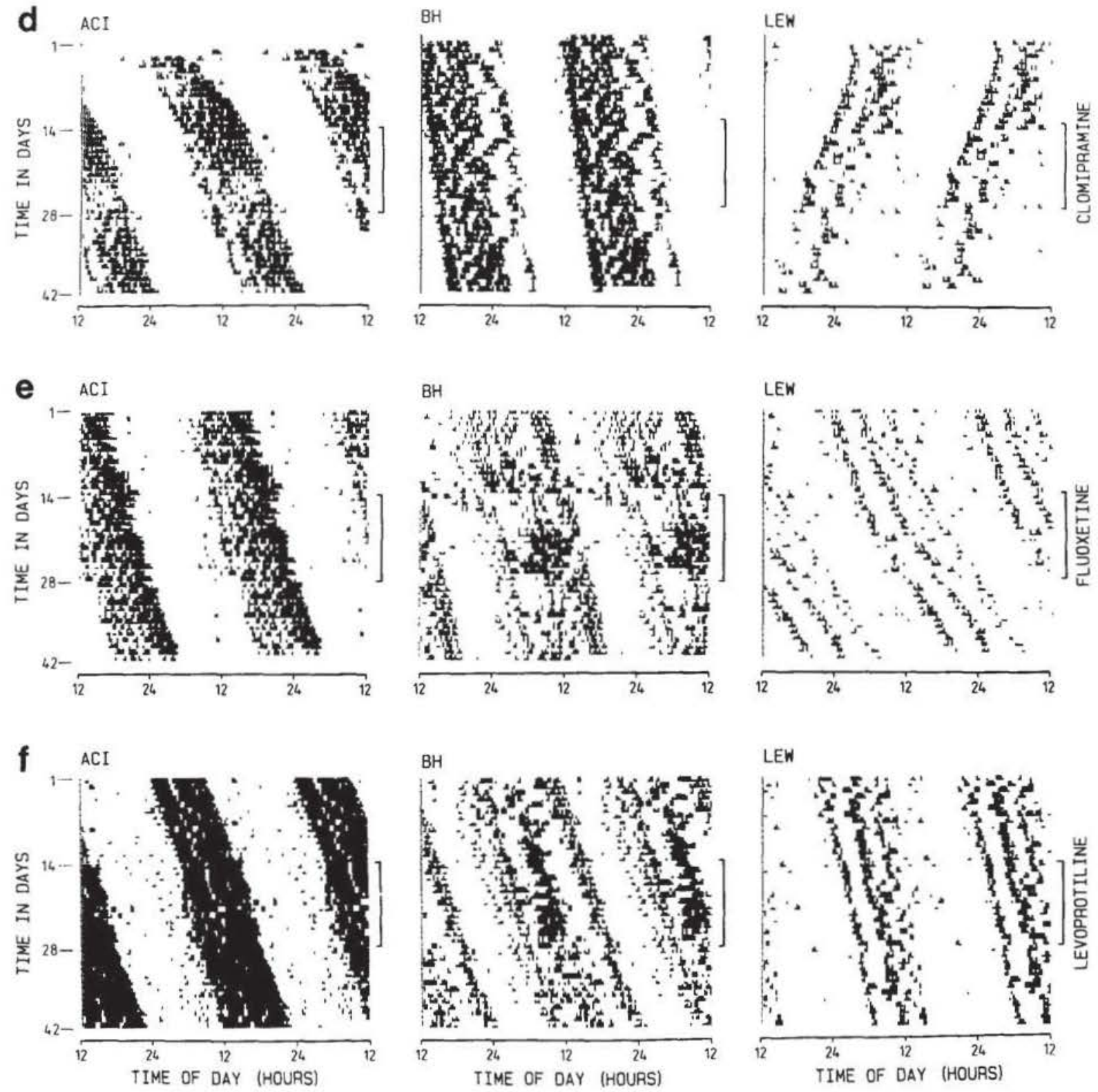

FIG. 1. Continued.

food intake was reduced mostly during drug treatment. The only substance to slightly increase food intake in all three strains was Ro 19-6327. Food intake data were used to estimate the average daily uptake rates of antidepressant agents summarized in Table 2. Average uptake rates were well within the expected range for moclobemide $(20 \mathrm{mg} / \mathrm{kg})$, Ro $19-6327$ $(2.5 \mathrm{mg} / \mathrm{kg})$, desipramine $(25 \mathrm{mg} / \mathrm{kg})$, fluoxetine $(10 \mathrm{mg} / \mathrm{kg})$, and levoprotiline $(30 \mathrm{mg} / \mathrm{kg})$. Only in the case of clomipramine was food intake dramatically reduced, resulting in an average drug intake of less than the expected rate of $30 \mathrm{mg} / \mathrm{kg}$.

\section{Strain Differences in Wheel-Running Activity}

Characteristic activity recordings from the various antidepressant treatments are shown in Figs. 1a-1f, where each recording represents one animal of a particular strain. During baseline conditions, all animals displayed clear free-running rhythms. As expected, the circadian pattern of wheel-running activity was highly strain dependent. Strain ACI exhibited the strongest activity rhythm characterized by a high activity level and well-defined activity onsets and offsets. Strain BH showed a weaker activity rhythm with blurred onsets and of fsets and expanded times of activity. The activity pattern of the LEW strain was characterized by two, sometimes three, short activity bouts about 4-5 h apart. When analyzed with the harmonic spectral analysis and the periodogram, characteristic frequencies were detected for each of the three strains. Periodogram analyses of the activity pattern of strain ACI revealed an average circadian period of $\tau=24 \mathrm{~h} 22 \mathrm{~min}$ during baseline conditions, whereas the free-running periods $\tau=24 \mathrm{~h} 15 \mathrm{~min}$ of strain BH and $\tau=24 \mathrm{~h} \mathrm{~S} \mathrm{~min} \mathrm{of} \mathrm{strain} \mathrm{LEW} \mathrm{were} \mathrm{generally}$ shorter. $\mathrm{BH}$ and LEW rats were characterized by additional 
TABLE 3

EFFECTS OF CHRONIC ANTIDEPRESSANT DRUG TREATMENT ON OVERALL ACTIVITY LEVEL (IMPULSES/DAY) AND DURATION OF ACTIVITY (mIn/DAY) IN ACl, BH, AND LEW RATS

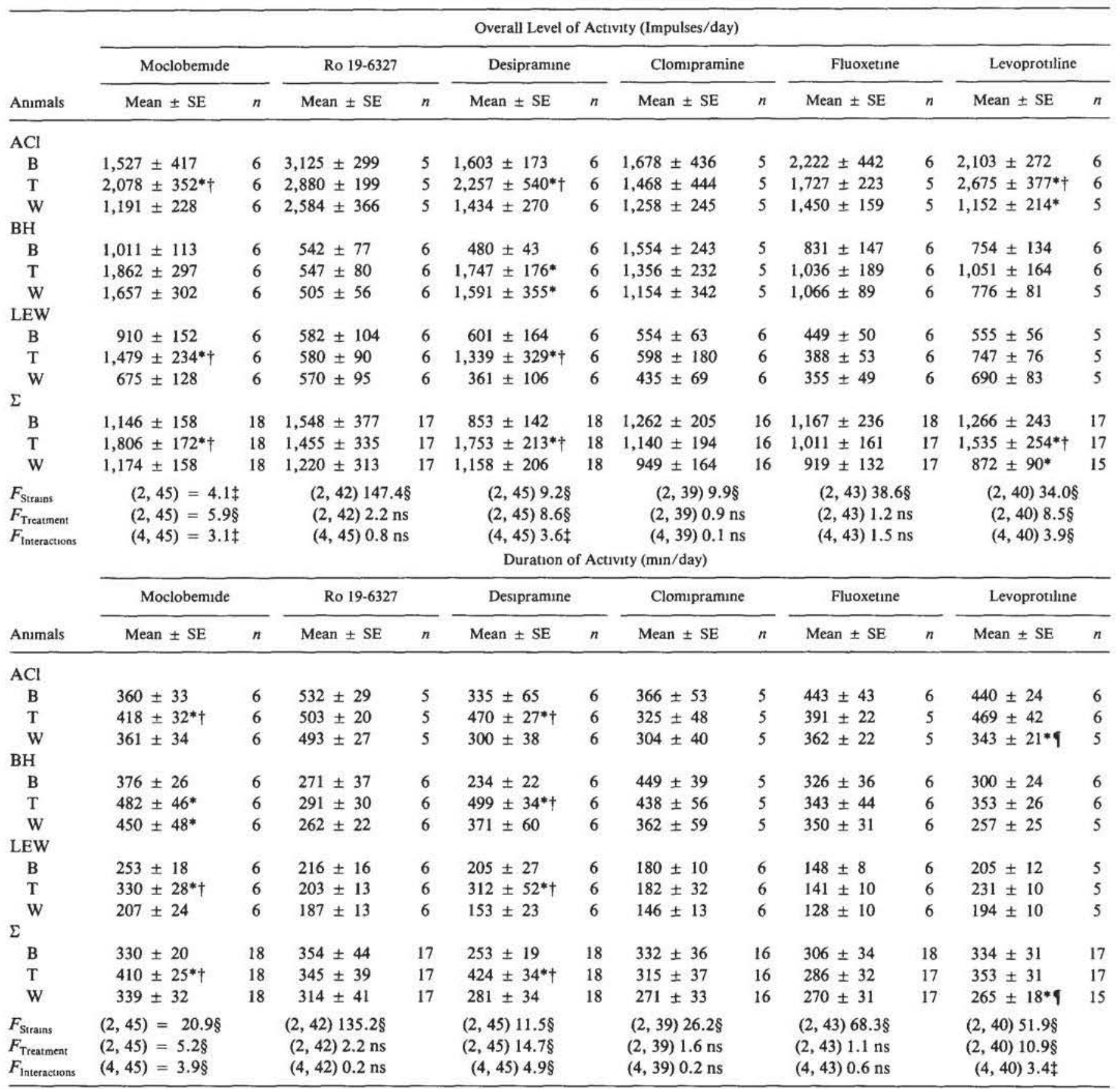

*Differences between strains, pharmacological treatments, and strain-treatment interactions were assessed using standard procedures of ANOVA (two-way ANOVA for repeated measurements). Comparısons of baseline (B), tratment (T), and withdrawal (W) conditions were performed using Tukey's multiple $t$-test. ns, not significant.

*Significant difference $(p \leq 0.05)$ from baseline condition.

†Significant difference from withdrawal.

$\ddagger p \leq 0.05$.

$\S p \leq 0.01$

SSignificant difference from treatment. 
a
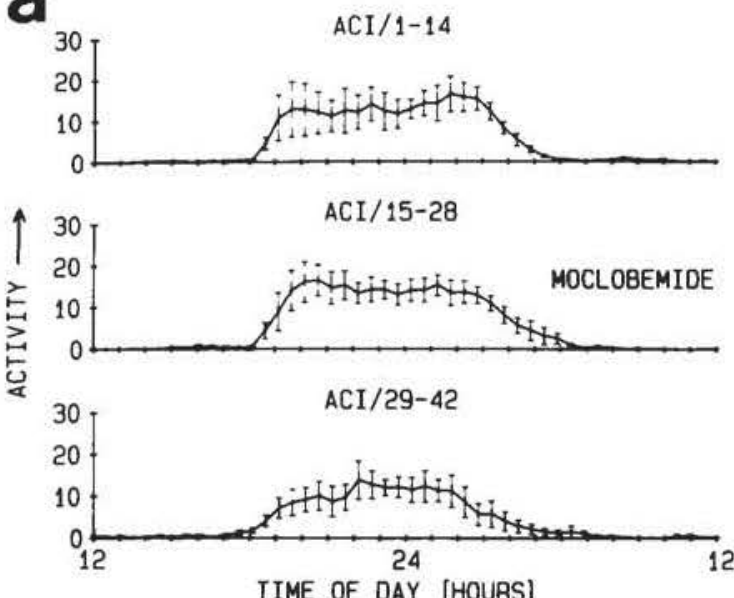

TIME OF DAY [HOURS]

C
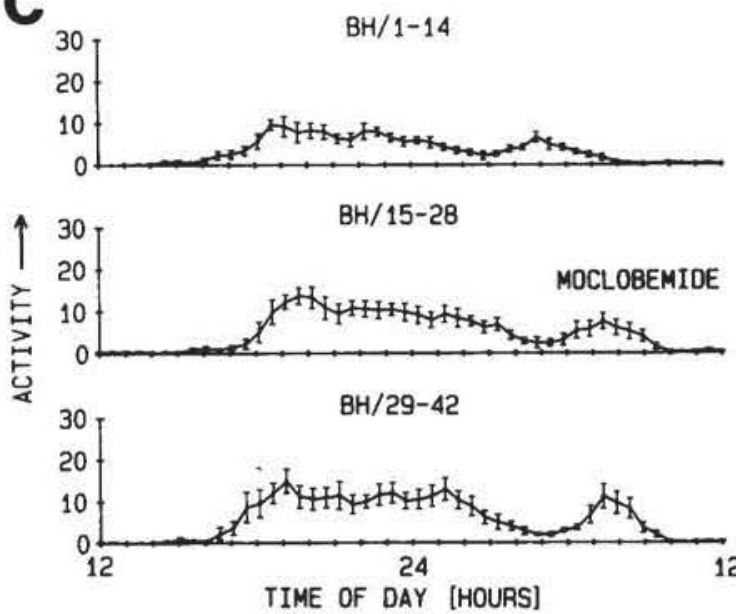

e
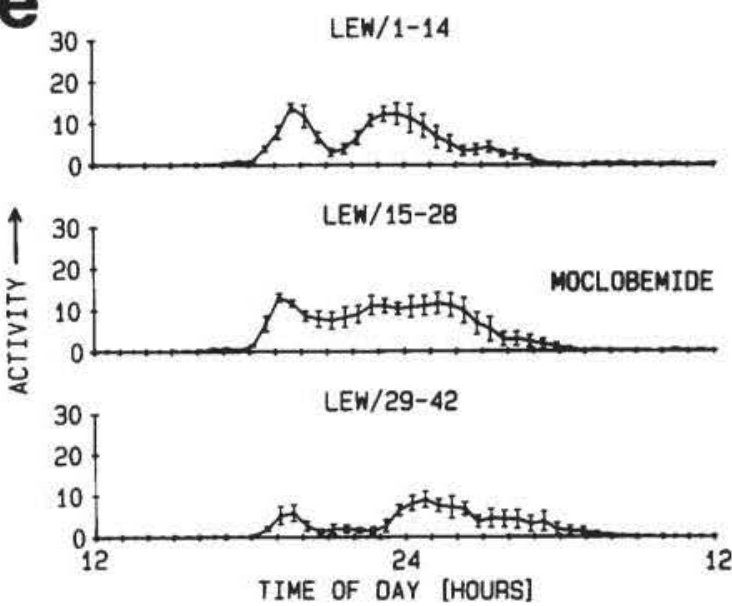

b

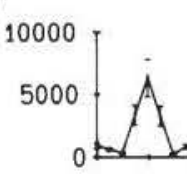

$\mathrm{ACI} / 1-14$
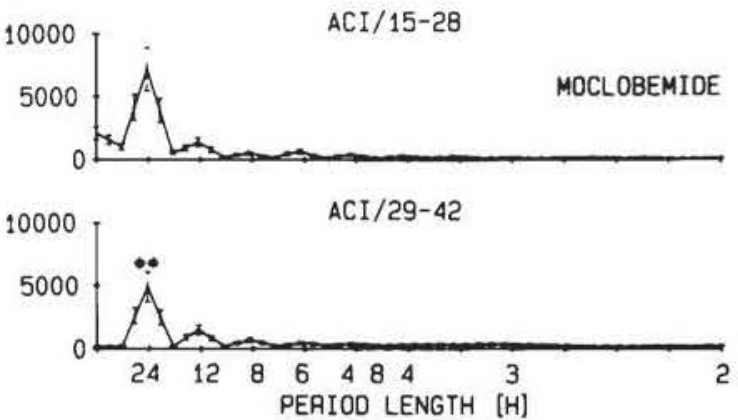

.
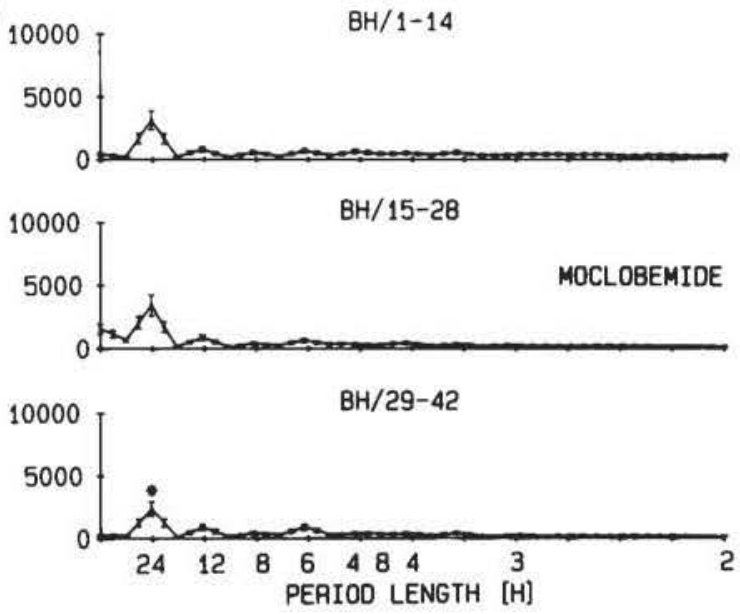

f
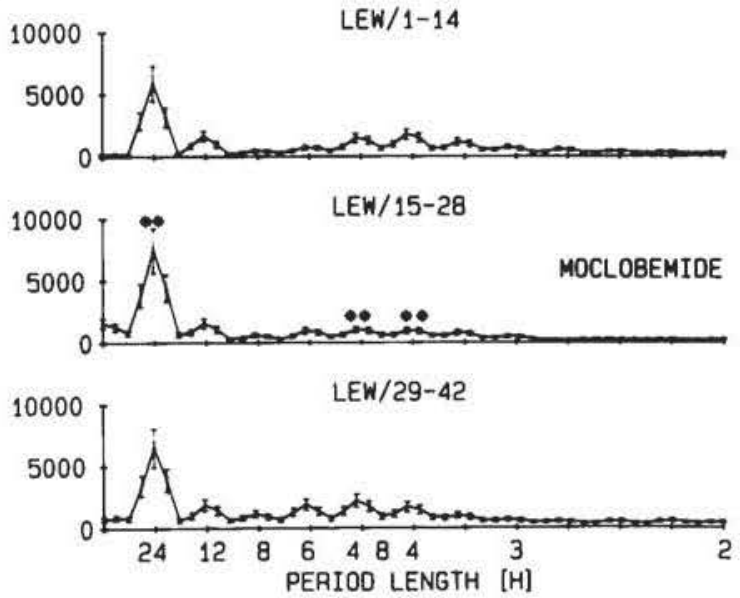

FIG. 2. Effects of moclobemide treatment. Left column: circadian waveform of wheel-running activity of $\mathrm{ACl}(\mathrm{a}, n=6), \mathrm{BH}$ (c), $n=6$ ), and LEW (e, $n=6$ ) rats during baseline conditions (upper panel), treatment (middle panel), and withdrawal (lower panel). Thirty-minute mean values are plotted as a function of the free-running period with standard deviation between animals shown as vertical lines. Right column: average power spectra for strains $\mathrm{ACl}(\mathrm{b}), \mathrm{BH}(\mathrm{d})$, and LEW (f) calculated from harmonic spectral analyses of individual animals. The $95 \%$ confidence limits of spectral estimates are plotted as vertical lines. Asterisks mark estimates that are significantly different from corresponding values during baseline conditions $\left({ }^{*} p<0.05 ;{ }^{* *} p<0.01\right)$. Amplitudes of spectral estimates: $\mathrm{ACl}-24 \mathrm{~h}_{\text {baselune }}=6,291 \pm 296,24-\mathrm{h}_{\text {moclobemide }}=7,168 \pm 299,24-\mathrm{h}_{\text {wrthdrawal }}=4,887 \pm 882$; BH-24-h $\mathrm{h}_{\text {bascline }}=3,127 \pm 339,24-\mathrm{h}_{\text {moclobemude }}=3,440 \pm 482,24-\mathrm{h}_{\text {wthdrawal }}=2,376 \pm 488 ;$ LEW $-24-\mathrm{h}_{\text {baseline }}=5,880 \pm 293$, $24-\mathrm{h}_{\text {moclobemide }}=7,436 \pm 177,24-\mathrm{h}_{\text {withdrawal }}=6,518 \pm 199 ; 4.8-\mathrm{h}_{\text {basecline }}=1,820 \pm 191,4.8-\mathrm{h}_{\text {mociobemide }}=882 \pm 214,4.8-\mathrm{h}_{\text {withdrawal }}$ $=2,365 \pm 189 ; 4-\mathrm{h}_{\text {baseline }}=2,134 \pm 183,4-\mathrm{h}_{\text {moclobemide }}=650 \pm 162,4-\mathrm{h}_{\text {mithdrawal }}=1,871 \pm 288$. 
TABLE 4

EFFECTS OF CHRONIC ANTIDEPRESSANT DRUG TREATMENT ON THE FREE-RUNNING PERIOD $\tau$ OF CIRCADIAN WHEEL-RUNNING ACTIVITY RHYTHMS IN ACl, BH, AND LEW RATS

\begin{tabular}{|c|c|c|c|c|c|c|c|c|c|c|c|c|}
\hline \multirow[b]{3}{*}{ Animals } & \multicolumn{12}{|c|}{ Free-Running Period (h) } \\
\hline & \multicolumn{2}{|l|}{ Moclobemide } & \multicolumn{2}{|l|}{ Ro $19-6327$} & \multicolumn{2}{|l|}{ Desipramine } & \multicolumn{2}{|c|}{ Clomipramine } & \multicolumn{2}{|l|}{ Fluoxetune } & \multicolumn{2}{|l|}{ Levoprotiline } \\
\hline & Mean $\pm \mathrm{SE}$ & $n$ & Mean \pm SE & $n$ & Mean $\pm \mathrm{SE}$ & $n$ & Mean $\pm \mathrm{SE}$ & $n$ & Mean $\pm \mathrm{SE}$ & $n$ & Mean $\pm \mathrm{SE}$ & $n$ \\
\hline \multicolumn{13}{|l|}{$\mathrm{ACl}$} \\
\hline B & $24.47 \pm 0.05$ & 6 & $24.42 \pm 0.03$ & 5 & $24.38 \pm 0.03$ & 6 & $24.43 \pm 0.12$ & 5 & $24.25 \pm 0.04$ & 6 & $24.29 \pm 0.02$ & 6 \\
\hline $\mathrm{T}$ & $24.35 \pm 0.05^{*}$ & 6 & $24.24 \pm 0.08$ & 5 & $24.29 \pm 0.02$ & 6 & $24.28 \pm 0.02$ & 5 & $24.22 \pm 0.07$ & 5 & $24.25 \pm 0.05$ & 6 \\
\hline W & $24.35 \pm 0.03^{*}$ & 6 & $24.38 \pm 0.04$ & 5 & $24.18 \pm 0.02^{*}$ & 6 & $24.45 \pm 0.03$ & 5 & $24.23 \pm 0.08$ & 5 & $24.45 \pm 0.05$ & 5 \\
\hline \multicolumn{13}{|l|}{$\mathrm{BH}$} \\
\hline B & $24.12 \pm 0.05$ & 6 & $24.38 \pm 0.09$ & 6 & $24.22 \pm 0.08$ & 6 & $24.18 \pm 0.03$ & 5 & $24.32 \pm 0.03$ & 6 & $24.32 \pm 0.04$ & 6 \\
\hline $\mathrm{T}$ & $23.95 \pm 0.03 * \dagger$ & 6 & $24.33 \pm 0.07$ & 6 & $23.87 \pm 0.07$ & 6 & $24.22 \pm 0.08$ & 5 & $24.28 \pm 0.03$ & 6 & $24.31 \pm 0.03$ & 6 \\
\hline w & $23.83 \pm 0.04 * \S$ & 6 & $24.33 \pm 0.09$ & 6 & $23.81 \pm 0.09^{*}$ & 6 & $24.23 \pm 0.07$ & 5 & $24.31 \pm 0.05$ & 6 & $24.23 \pm 0.06$ & 5 \\
\hline \multicolumn{13}{|l|}{ LEW } \\
\hline B & $23.78 \pm 0.02$ & 6 & $24.21 \pm 0.05$ & 6 & $24.02 \pm 0.06$ & 6 & $23.73 \pm 0.1$ & 6 & $24.34 \pm 0.04$ & 6 & $24.22 \pm 0.04$ & 5 \\
\hline $\mathbf{T}$ & $23.65 \pm 0.03^{*}$ & 6 & $24.27 \pm 0.04$ & 6 & $23.69 \pm 0.09^{*}$ & 6 & $23.95 \pm 0.07$ & 6 & $24.51 \pm 0.05$ & 6 & $24.22 \pm 0.02$ & 5 \\
\hline W & $23.68 \pm 0.05^{*}$ & 6 & $24.29 \pm 0.21$ & 6 & $23.71 \pm 0.14^{*}$ & 6 & $23.75 \pm 0.17$ & 6 & $24.57 \pm 0.04$ & 6 & $24.29 \pm 0.04$ & 5 \\
\hline \multicolumn{13}{|c|}{ 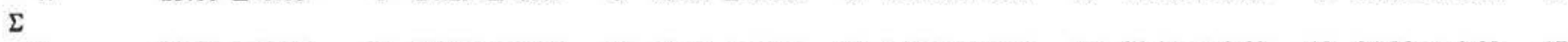 } \\
\hline B & $24.12 \pm 0.07$ & 18 & $24.35 \pm 0.04$ & 17 & $24.19 \pm 0.05$ & 18 & $24.16 \pm 0.09$ & 16 & $24.31 \pm 0.02$ & 18 & $24.28 \pm 0.02$ & 17 \\
\hline $\mathrm{T}$ & $23.98 \pm 0.07^{*}$ & 18 & $24.27 \pm 0.04$ & 17 & $23.94 \pm 0.07^{*}$ & 18 & $24.15 \pm 0.05$ & 16 & $24.34 \pm 0.04$ & 17 & $24.26 \pm 0.02$ & 17 \\
\hline W & $23.95 \pm 0.07^{*}$ & 18 & $24.34 \pm 0.04$ & 17 & $23.89 \pm 0.07^{*}$ & 18 & $24.14 \pm 0.09$ & 16 & $24.37 \pm 0.05$ & 17 & $24.32 \pm 0.03$ & 15 \\
\hline$F_{\text {Strans }}$ & $(2,45)=20.8 \S$ & & $(2,42) 1.6 \mathrm{~ns}$ & & $(2,45) 26.8 \S$ & & $(2,39) 31.9$ & & $(2,43) 19.7$ & & $(2,40) 2.9 n$ & \\
\hline$F_{\text {Trearment }}$ & $(2,45)=14.88$ & & $(2,42) 1.0 \mathrm{~ns}$ & & $(2,45) 13.18$ & & $(2,39) 0.1 \mathrm{n}$ & & $(2,43) 1.3 n$ & & $(2,40) 1.9 n$ & \\
\hline$F_{\text {Interactions }}$ & $(4,45)=2.7 \ddagger$ & & $(4,42) 1.0 \mathrm{~ns}$ & & $(4,45) 3.3 \ddagger$ & & $(4,39) 1.4 n$ & & $(4,43) 2.3 n$ & & $(4,40) 1.3 n$ & \\
\hline
\end{tabular}

For methods and notations, see Table 3.

rhythmic components of approximately 12 and $6 \mathrm{~h}$ and 4.8 and $4 \mathrm{~h}$, respectively.

\section{Effects of Antidepressants on Circadian Rhythms}

Of the antidepressant agents tested, only two, moclobemide and desipramine, clearly affected parameters of circadian wheel running activity (Figs. 1a-1f). The effects of drug treatment on the overall level and duration of activity are summarized in Table 3.

Chronic treatment with moclobemide induced significant changes in the overall level, $F(2,45)=5.9, p<0.01$, and duration of activity, $F(2,45)=5.2, p<0.01$, in all three strains. Tukey's multiple $t$-test revealed a significant increase in the overall level and duration of activity during moclobemide treatment compared to both baseline and withdrawal conditions and no significant differences between baseline and withdrawal. Figures $2 \mathrm{a}-2 \mathrm{f}$ illustrate the average waveform of circadian activity and pooled power spectra of each strain during baseline condition, moclobemide treatment, and withdrawal. In all three strains, moclobemide treatment resulted in an increase of the amplitude of the circadian waveform. In the power spectrum analysis, this is expressed by an increase of the 24-h peak. In addition, moclobemide treatment altered the pattern of activity in the LEW strain. As shown in Fig. $2 \mathrm{e}$, moclobemide treatment changed the characteristic multimodal activity pattern of the LEW strain during baseline conditions into a unimodal activity pattern similar to that of the control strain ACI. This effect disappeared after terminating the treatment. Power spectrum analysis confirmed these findings (Fig. 2f). The amplitude of the 24 -h peak was increased during moclobemide treatment, whereas the characteristic peaks at 4 and $4.8 \mathrm{~h}$ were reduced to nonsignificant levels.
Results for free-running period are summarized in Table 4. Two-way ANOVA revealed significant strain differences, $F(2$, $45)=20.8, p<0.01$, as well as significant effects of treatment, $F(2,45)=14.8, p<0.01$. Multiple $t$-test comparisons revealed a small but significant shortening $(8 \mathrm{~min})$ of the freerunning period during moclobemide treatment. However, this effect was not reversed during withdrawal.

Total drug intake over the 2 weeks of moclobemide treatment was not significantly correlated with moclobemideinduced alterations in any of the circadian parameters measured. Furthermore, when evaluating the data for possible relationships between baseline values and treatment-induced alterations no significant pairwise correlations could be detected between baseline values and treatment effects for either overall activity level, duration, or free-running period.

Desipramine had even more dramatic effects on the circadian wheel-running rhythm of all three strains than moclobemide (Figs. 1c and 3). Desipramine treatment caused a significant increase in the overall level, $F(2,45)=8.6, p<0.01$, and duration of activity, $F(2,45)=14.7, p<0.01$ (Table 3 ). Total drug intake over the 2 weeks of desipramine treatment was positively correlated with drug-induced changes in overall level $(r=0.77, p<0.01)$ and duration $(r=0.75$, $p<0.01$ ) of activity. No significant correlation could be detected between baseline values and desipramine-induced effects for any of the circadian parameters tested. Similar to moclobemide, desipramine treatment affected the average pattern of circadian activity in all three strains. In ACI and LEW strains, the amplitude of the 24-h peak was increased during desipramine treatment, although this increase did not prove significant (Figs. $3 \mathrm{~b}$ and $3 \mathrm{f}$ ). The effect of desipramine treatment was most pronounced for the multimodal activity pattern of the LEW strain. As shown in Fig. 3e, desipramine 
a
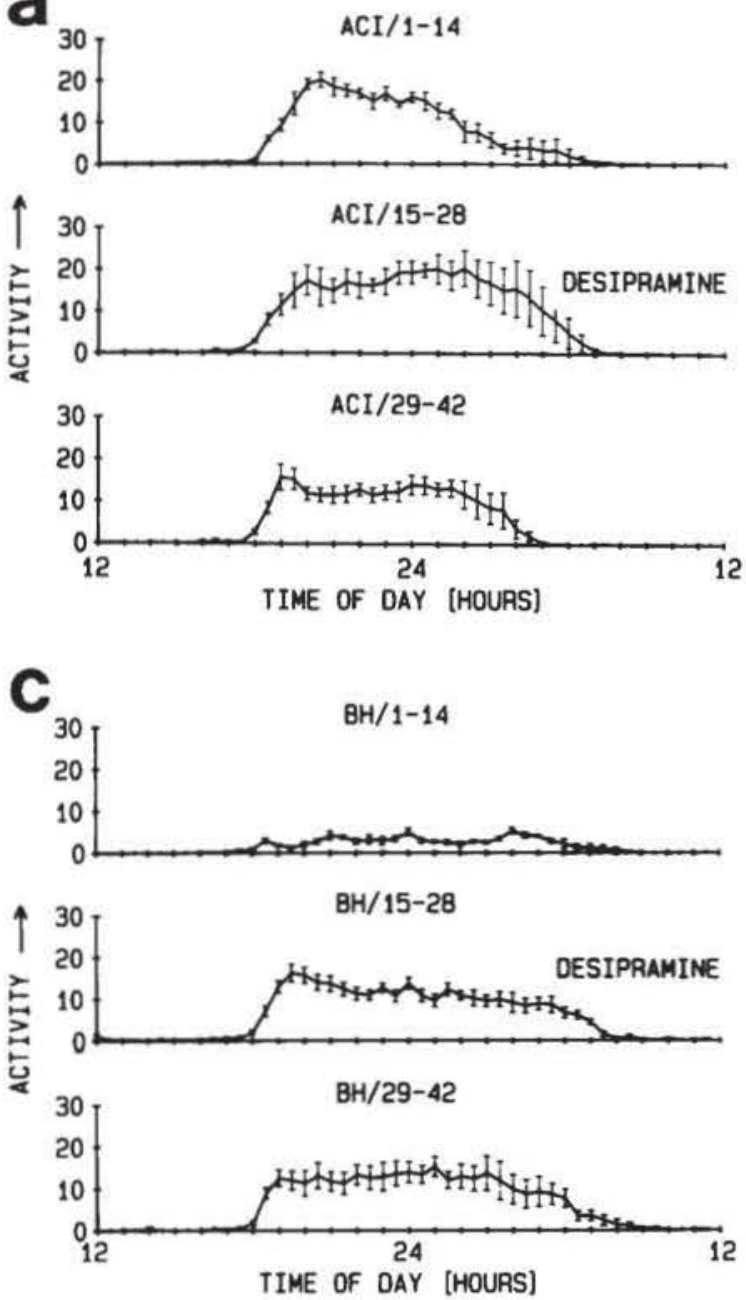

e
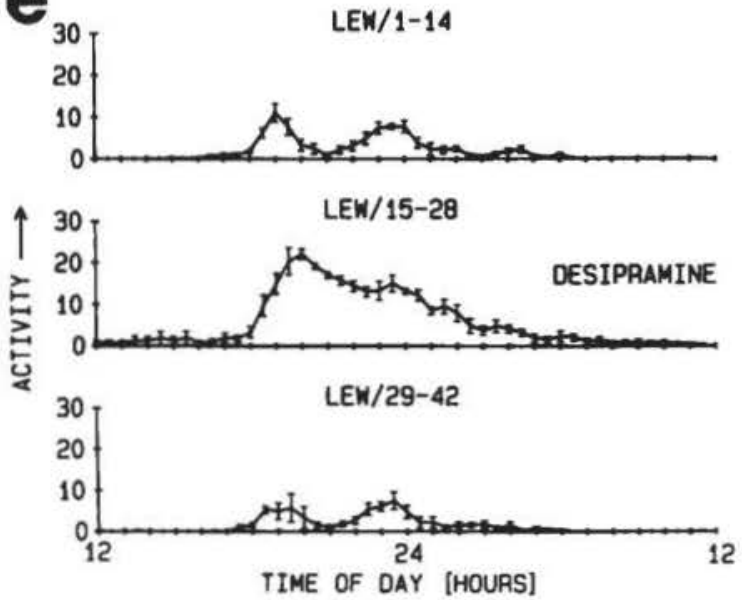

b
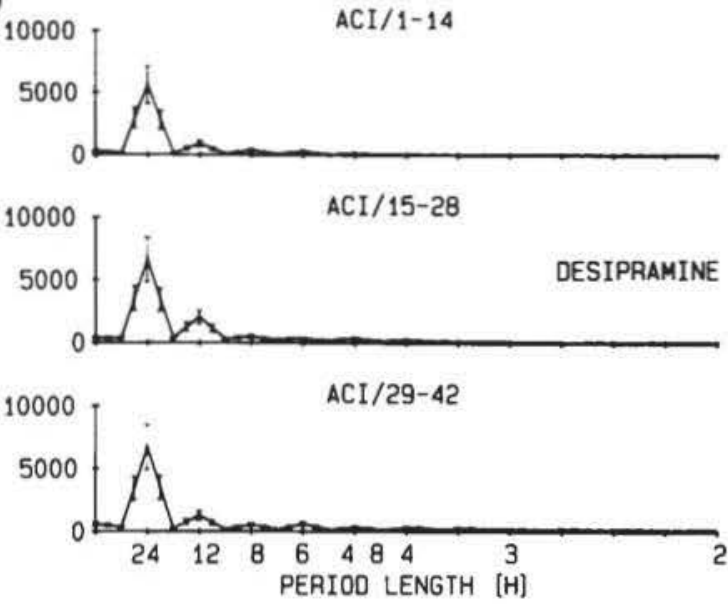

d
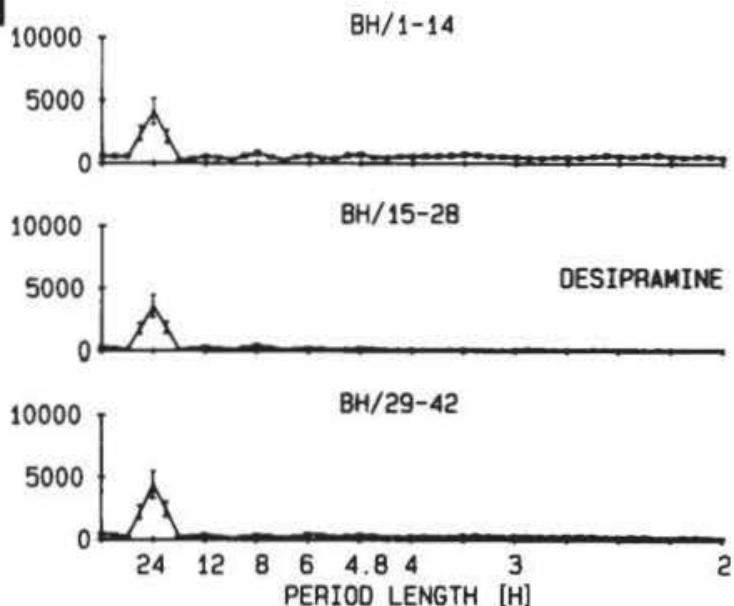

\{
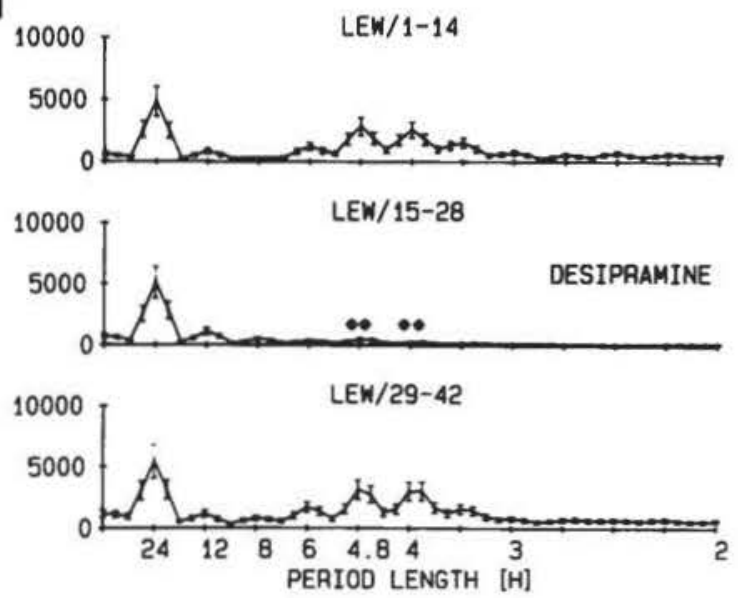

FIG. 3. Effects of desipramine treatment. Circadian waveform of wheel-running activity and harmonic spectral analyses of ACl (a,b $n=6), \mathrm{BH}(\mathrm{c}, \mathrm{d} n=6)$, and LEW (e,f $n=6$ ) rats during baseline conditions (upper panel), treatment (middle panel), and withdrawal (lower panel). Amplitudes of spectral estimates: $\mathrm{ACl}-24 \mathrm{~h}_{\text {bustine }}=5,610 \pm 544,24 \mathrm{~h}_{\text {desipramixe }}=6,617 \pm 461$, $24-h=6,100 \pm 394 ; \quad B H-24 h_{\text {basche }}=4,128 \pm 234, \quad 24$ h $_{\text {desupramine }}=3,576 \pm 210, \quad 24-h_{\text {withdrawal }}=4,407 \pm 339$; $\mathrm{LEW}-24-\mathrm{h}_{\text {baseline }}=4,863 \pm 558,24-\mathrm{h}_{\text {despramune }}=5,431 \pm 351,24 \mathrm{~h}_{\text {wnthdrawal }}=5,134 \pm 568 ; 4.8-\mathrm{h}_{\text {beseline }}=3,642 \pm 635,4.8-$ $\mathrm{h}_{\text {despramine }}=490 \pm 159,4.8-\mathrm{h}_{\text {withdrawal }}=3,140 \pm 314 ; 4-\mathrm{h}_{\text {beseline }}=2,606 \pm 285,4-\mathrm{h}_{\text {deapramme }}=259 \pm 68,4-\mathrm{h}_{\text {wrthdrawal }}=3,007$ \pm 570; For further explanations, see Fig. 2. 
treatment of LEW rats resulted in a unimodal activity pattern similar to that seen in ACI rats during baseline and withdrawal condition. Power spectrum analyses confirmed these results (Fig. 3f). The characteristic peaks at 4.8 and $4 \mathrm{~h}$ detected during baseline and withdrawal were completely absent during desipramine treatment.

Furthermore, desipramine treatment clearly affected the free-running period of all three strains (Fig. 1c and Table 4). ANOVA revealed a significant shortening of $\tau$ during desipramine treatment (ACI $\Delta \tau=-5 \mathrm{~min} ; \mathrm{BH} \Delta \tau=-20 \mathrm{~min}$; LEW $\Delta \tau=-13 \mathrm{~min}$ ). Remarkably, this effect persisted during the first 2 weeks of withdrawal. Because the experiment was terminated after 42 days, it is not known whether the shortening of $\tau$ would have returned to baseline values after a longer period of drug withdrawal.

All other substances tested, that is, Ro 19-6327, clomipramine, fluoxetine, and levoprotiline, failed to induce systematic changes in the circadian wheel-running rhythm of all of the three strains (Figs. 1b and 1d-f). Repeated two-way ANOVA revealed significant changes only during levoprotiline treatment, where a small increase in the overall level and duration of activity was found (Table 3 ).

\section{DISCUSSION}

This study investigated the effects of various clinically effective antidepressants on circadian activity rhythms in specific inbred strains of laboratory rats. The objective was to possibly identify effects common to all of them. Of the six substances tested, only two, moclobemide and desipramine, induced significant changes in parameters of wheel-running activity. Both agents increased the overall level, as well as the duration, of activity. Although these effects were observed in all three strains, they were most pronounced in the LEW strain, which had the lowest activity level and the shortest duration of activity during baseline conditions. Furthermore, both agents affected the activity pattern of LEW rats, changing the rather unusual multimodal pattern into the unimodal pattern normally seen in laboratory rats. Specifically, the characteristic periodic components of 4 and $4.8 \mathrm{~h}$ were absent during treatment.

Moclobemide and desipramine also induced a shortening of the free-running period. From what is presently known, a shortening of the free-running period of the circadian pacemaker causes an advance of the phase position of entrained rhythms (28). A recent investigation (3) of desipramine treatment in rats (also administered via food; however, in a twofold concentration compared to the present study) indeed showed a phase advance ( $+70 \mathrm{~min}$ ) of the temperature rhythm under LD entrainment, supporting our finding that desipramine affects the period of the circadian pacemaker. Moreover, the study also failed to demonstrate an effect of clomipramine (again given in a twofold concentration) on the phase of temperature rhythms, consistent with our finding that clomipramine does not affect the free-running period.

However, there are also a few incongruencies that need to be discussed. First, in the present study the period shortening during desipramine and moclobemide treatment was not reversed during withdrawal conditions. Whether or not these period changes were due to other effects, for example, aging of animals, could have been clarified by including a nontreatment control group to monitor the extent of spontaneous changes in the period. However, because no such changes were observed for the other ineffective antidepressant agents, which could thus be regarded as controls, the period shortening appears to be a true effect of the drug treatment.

Second, the rather convenient procedure of drug application via food does not allow precise drug dosage because it includes the possibility of drug self-administration or food aversion due to the unfamiliar flavor or task of the food. Except in the case of Ro 19-6327, drug treatment resulted in a decline of food consumption and halt or decline of body weight, both of which returned to baseline levels after treatment termination. These are typical effects of flavor or task aversion. However, it seems unlıkely that the changes during moclobemide and desipramine treatment were only side effects of the reduced food intake and body weight because a similar reduction was seen for other agents that did not affect circadian rhythm parameters. Nevertheless, it would be desirable to verify that the effects of moclobemide and desipramine treatment seen in the present study can be reproduced under continuous drug administration using implanted osmotic pumps.

In the present study, Ro 19-6327, clomipramine, fluoxetine, and levoprotiline failed to have an effect on circadian wheel-running rhythms. The negative result for Ro 19-6327 could have been expected because of the positive effect of moclobemide. The enzyme MAO exists in two catalytically distinguishable forms called MAO-A and MAO-B. MAO-A prefers serotonin and norepinephrine as substrates and is selectively inhibited by moclobemide $(4,5,32)$. MAO-B preferentially deaminates phenylethylamine and benzylamine and is selectively inhibited by Ro 19-6327 (14). Therefore, the different effects of moclobemide and Ro 19-6327 on circadian rhythms are consistent with the pharmacological profiles of these drugs. In the case of clomipramine, fluoxetine, and levoprotiline, it cannot be excluded that the negative results were due to an ineffective dosage of these substances. However, previous studies have demonstrated pharmacological effects successfully with the same dosages used in the present study. Repeated administration of $10 \mathrm{mg} / \mathrm{kg}$ clomipramine induces a $90 \%$ inhibition of serotonin reuptake in the rat brain with only small effects on norepinephrine and dopamine reuptake (49). At doses of 5 and $10 \mathrm{mg} / \mathrm{kg}$, fluoxetine, too, very selectively inhibits serotonin reuptake in the rat brain and increases extracellular serotonin concentrations 3 - and 13 -fold, respectively $(11,49)$. The negative results of the levoprotiline treatment are difficult to interpret because the pharmacological mechanisms of levoprotiline are still unknown. A major problem is that antidepressant-like effects have been demonstrated for the (-)-enantiomer of oxaprotiline, that is, levoprotiline, at doses between 1 and $30 \mathrm{mg} / \mathrm{kg}$, while pharmacological activities, such as selective inhibition of norepinephrine reuptake, have been found to reside in the $(+)$-enantiomer $(6,21)$. Because the doses used in the present study are known to be pharmacologically effective, the negative results of Ro 19-6327, clomipramine, fluoxetine, and levoprotiline suggest that the different types of antidepressant drugs have a more selective effect on the circadian timing system than previously assumed.

The results of this study do not support the so-called phaseadvance hypothesis of depression. According to this hypothesis, disturbances of circadian rhythms in depressive patients are interpreted as phase advanced with respect to the environmental day-night cycle $(27,39,41-43)$, and the clinical efficacy of the most widely used antidepressant drugs are due to their ability to lengthen the free-running period as well as delay the entrainment phase of circadian rhythms. However, of the six antidepressants tested in the present study only two, moclobemide and desipramine, induced significant changes in the free- 
running period. In addition, the period was shortened rather than lengthened and, what seems even more important, the effect was not reversed after termination of drug treatment.

The discrepancy between these results and previous findings needs further investigation. To date, most of the work on the effects of antidepressants on circadian rhythms in animals has focused on lithium, clorgyline, or imipramine, but the results are rather inconsistent (8). Some studies found that lithium lengthens the free-running period of circadian rhythms in various species, whereas others did not [for summaries, see $(8,43,44)]$. Similarly inconsistent results have been reported for imipramine, an unspecific monoamine reuptake inhibitor. In rats, imipramine delays the phase position of many brain receptor rhythms (43) and restores abnormally phaseadvanced endocrine rhythms of isolation-stressed rats to the normal phases found in controls (13). On the other hand, imipramine did not affect the phase position or rate of reentrainment of circadian activity rhythms in hamsters (2), and no significant effects on the period length could be observed in rats (36) or hamsters (45). In the case of clorgyline, an irreversible type A MAO inhibitor, a lengthening and phase delay of circadian activity rhythms have been demonstrated only in hamsters $(7,37,45)$, while no clear effect on the period length was found in rats (29). One explanation for this species difference may be that the hamster brain contains more than $95 \%$ MAO type A (10), whereas the rat brain contains only about $60-80 \%$ MAO type A $(10,32)$. It has also been suggested that timing and mode of administration may be critical to the efficacy of a drug to alter the circadian period (8). For example, continuous infusion of lithium seems to be less effective than intermittent application via food or drinking water (8).

Another open issue is the primary site of action of these drugs. Do they act on the circadian pacemaker itself or merely through changes in the general physiological status of the animals? So far, alterations of the free-running period have mostly been ascribed to a direct effect on the circadian pacemaker. However, in light of recent observations that behavioral arousal may produce feedback effects on the circadian pacemaker of hamsters $(24,38)$ changes in the free-running period may also be induced by alterations of the activity level. In the present study, moclobemide and desipramine induced an increase in the overall level of activity and a shortening of the free-running period. Estrogen, too, has been found to increase the activity level and shorten the free-running period in hamsters (23) and rats (1). Clorgyline, on the other hand, decreased the level of activity and lengthened the free-running period in hamsters $(7,45)$. Free-running periods can be affected even without any drug treatment merely by the method of the activity recording. For instance, access to a running wheel has been shown to increase the level of activity and shorten the free-running period in rats (50). A negative correlation between the number of wheel revolutions and the freerunning period has also been observed in mice (9). All these findings suggest that pharmacological agents may affect the circadian clock indirectly through an increase or decrease of the activity level. Unfortunately, even today only few investigations of pharmacological effects on circadian rhythms make use of computerized recording equipment that would allow a thorough evaluation of the relationship between alterations in activity levels and the free-running period (9).

The most important finding of the present study appears to be the restoration of a unimodal activity pattern in LEW rats by moclobemide and desipramine. Previous investigations of LEW rats suggest that the unusual activity pattern of this strain is caused by a distinct coupling of multiple circadian oscillators $(34,46,47)$. However, the neurophysiological or neurochemical mechanisms underlying the unusual activity pattern of the LEW strain are still unknown. Considering that both moclobemide and desipramine altered the abnormal multimodal activity pattern of LEW rats into a unimodal pattern like that seen in other laboratory rats, it is conceivable that at least some of the abnormal features of activity rhythms in this strain are caused by modifications of the noradrenergic system. In rats, moclobemide, a reversible and highly selective MAO type A inhibitor, increases serotonin $(+30 \%)$ as well as norepinephrine $(+25 \%)$ and dopamine levels $(+5 \%)$ and dramatically reduces all monoamine metabolites $(-80 \%)$ $(4,5)$. Desipramine inhibits the reuptake of norepinephrine as well as of serotonin at the presynaptic terminals, but the inhibition of norepinephrine is 1,000 times more effective than for serotonin $(17,21)$. Moclobemide and desipramine both act in a similar neurochemical way, enhancing noradrenergic transmission. The critical synapses mediating these effects may be located within or in the vicinity of the hypothalamic suprachiasmatic nucleus ( $\mathrm{SCN}$ ), the locus of an identified circadian pacemaker in the vertebrate nervous system $(22,31)$. Noradrenergic fibers have been found to build a "capsule" of innervation around the SCN (40), and at least some SCN neurons are electrically responsive to iontophoretically applied norepinephrine (33). Further investigations should, therefore, be undertaken to identify the anatomic loci and cellular mechanisms of the effects described in this study.

In conclusion, the present study found that some antidepressives affect parameters of circadian rhythmicity. However, it could not demonstrate a common effect on all classes of antidepressives. Nevertheless, these substances certainly provide a powerful tool for investigating the neural mechanisms underlying circadian rhythms. The effects of moclobemide and desipramine indicate that level and period of circadian activity rhythms are influenced by the noradrenergic system. Furthermore, the changes these drugs cause in the multimodal activity pattern of LEW rats suggest that the effects of antidepressant agents depend upon the genetic background of animals.

\section{ACKNOWLEDGEMENTS}

This research was supported by a grant from the Deutsche Forschungsgemeinschaft (Wo-354/3-2) and by additional funding from F. Hoffmann-La Roche Ltd., Basel, Switzerland, who also generously supplied the moclobemide, Ro 19-6327, desipramine, and clomipramine. Fluoxetine was generously supplied by Lilly, Indianapolis, IN, and levoprotiline was generously supplied by CIBA-GEIGY Ltd., Basel, Switzerland. The author thanks Rita Hellmann for technical assistance, Andreas Herrmann for help in preparing the manuscript, and Prof. W. Haefely, Prof. M. Da Prada, and Dr. R. Scherschlicht of Hoffmann-La Roche for valuable contributions to an earlier version of the manuscript.

\section{REFERENCES}

1. Albers, H. E. Gonadal hormones organize and modulate the circadian system of the rat. Am. J. Physiol. 241:R62-R66; 1981.

2. Aschoff, J. Circadian activity rhythm in hamsters unaffected by imipramine. In: Hildebrandt, G.; Moog, R.; Raschke, F., eds. Chronobiology and chronomedicine. Frankfurt/Main: Peter Lang; 1986:243-247. 
3. Brown, G. M.; Seggie, J. Effects of antidepressants on entrainment of circadian rhythms. Prog. Neuropsychopharmacol. Biol. Psychiatry 12:299-306; 1988.

4. Da Prada, M.; Kettler, R.; Burkard, W. P.; Lorez, H. P.; Haefely, W. Some basic aspects of reversible inhibitors of monoamine oxidase-A. Acta Psychiatr. Scand. 82(suppl. 360):7-12; 1990.

5. Da Prada, M.; Kettler, R.; Keller, H. H.; Burkard, W. P.; Muggli-Maniglio, D.; Haefely, W. E. Neurochemical profile of moclobemide, a short-acting and reversible inhibitor of monoamine oxidase type A. J. Pharmacol. Exp. Ther. 248:400-414; 1989.

6. Delini-Stula, A.; Hauser, K.; Baumann, P.; Olpe, H.-R.; Waldmeier, P.; Storn, A. Stereospecificity of behavioural and biochemical responses to oxaprotilne-a new antidepressant. In: Costa, E.; Racagnı, G., eds. Typical and atypical antidepressants: Molecular mechanisms. New York: Raven Press; 1982:265-275.

7. Duncan, W. C.; Tamarkin, L.; Sokolove, P. G.; Wehr, T. A. Chronic clorgyline treatment of syrian hamsters: An analysis of effects on the circadian pacemaker. J. Biol. Rhythms 3:305-322; 1988.

8. Duncan, W. C.; Wehr, T. A. Pharmacological and nonpharmacological chronotherapies of depression. In: Reinberg, A.; Smolensky, M.; Labreque, G., eds. Annual review of chronopharmacology. vol. 4. Oxford, UK: Pergamon Press; 1987:137170.

9. Edgar, D. M.; Martin, C. E.; Dement, W. C. Actıvity feedback to the mammalian circadian pacemaker: Influence on observed measures of rhythm period length. J. Biol. Rhythms 6:185-199; 1991.

10. Edwards, D. J.; Malsbury, C. W. Characteristics of monoamine oxidases in brain and other organs of the golden hamster. Biochem. Pharmacol. 27:959-963; 1978.

11. Fuller, R. W.; Wong, D. T.; Robertson, D. W. Fluoxetine, a selective inhibitor of serotonin uptake. Med. Res. Rev. 11:17-34; 1991.

12. Goodwin, F. K.; Wirz-Justice, A.; Wehr, T. A. Evidence that the pathophysiology of depression and the mechanism of action of antidepressant drugs both involve alterations in circadian rhythms. In: Costa, E.; Racagni, G., eds. Typical and atypical antidepressants: Clinical practice. New York: Raven Press; 1982: 1-11.

13. Greco, A. M.; Gambardella, P.; Sticchi, R.; D'Aponte, D.; de Franciscis, P. Chronic administration of imipramine antagonizes deranged circadian rhythm phases in individually housed rats. Physiol. Behav. 48:67-72; 1990.

14. Haefely, W. E.; Kettler, R.; Keller, H. H.; Da Prada, M. Ro $19-6327$, a reversible and highly selective monoamine oxidase B inhibitor: A novel tool to explore the MAO-B function in humans. In: Streifler, M. B.; Korczyn, A. D.; Melamed, E.; Youdım, M. B. H., eds. Advances in neurology. vol. 53. Parkinson's disease: Anatomy, pathology, and therapy. New York: Raven Press; 1990:505-512.

15. Halberg, F.; Panofsky, H. I. Thermo variance-spectra; methods and clinical illustrations. Exp. Med. Surg. 19:285-321; 1961.

16. Hallonquist, J. D.; Goldberg, M. A.; Brandes, J. S. Affective disorders and circadian rhythms. Can. J. Psychiatry 31:259-272; 1986.

17. Harms, H. H. The antidepressant agents desipramine, fluoxetine, fluvoxamine and norzimelidine inhibit uptake of $\left[{ }^{3} \mathrm{H}\right]$ noradrenaline and $\left[{ }^{3} \mathrm{H}\right]$-hydroxytryptamine in slices of human and rat cort1cal brain tissue. Brain Res. 275:99-104; 1983.

18. Kripke, D. F.; Mullaney, D. J.; Gabriel, S. The chronopharmacology of antidepressant drugs. In: Reinberg, A.; Smolensky, M.; Labreque, G., eds. Annual review of chronopharmacology. vol. 2. Oxford, UK: Pergamon Press; 1985:275-289.

19. Kripke, D. F.; Wyborney, V. G. Lithium slows rat circadian activity rhythms. Life Sci. 26:1319-1321; 1980.

20. Lewy, A. J.; Sack, R. L.; Singer, C. M.; White, D. M.; Hoban, T. M. Winter depression and the phase-shift hypothesis for bright light's therapeutic effects: History, theory and experimental evidence. J. Biol. Rhythms 3:121-134; 1988.

21. Maitre, L.; van Riezen, H. Amine re-uptake block by antidepres- sant: Virtue or vice? In: Leonard, B.; Spencer, P., eds. Antidepressants: Thirty years on. London, UK: Clinical Neuroscience Publishers; 1990:60-70.

22. Meijer, J. H.; Rietveld, W. J. Neurophysiology of the suprachiasmatic circadian pacemaker in rodents. Physiol. Rev. 69:671-707; 1989.

23. Morm, L. P.; Fitzgerald, K. M.; Zucker, I. Estradiol shortens the period of hamster circadian rhythms. Science 196:305-307; 1977.

24. Mrosovsky, N.; Reebs, S. G.; Honrado, G. I.; Salmon, P. A. Behavioural entrainment of circadian rhythms. Experientıa 45: 696-702; 1989.

25. O'Donohue, T. L.; Wırz-Justıce, A.; Kafka, M. S.; Naber, D.; Campbell, I. C.; Wehr, T. A. Effects of chronic lithium, clorgyline, imipramine, fluphenazine and constant darkness on the $\alpha$ melanotropin content and circadian rhythms in rat brain. Eur. J. Pharmacol. 85:1-7; 1982.

26. Panofsky, H.; Halberg, F. II. Thermo-variance spectra; simplified computational example and other methodology. Exp. Med. Surg. 19:322-338; 1961 .

27. Papoušek, M. Chronobiologische Aspekte der Zyklothymie. Fortschr. Neurol. Psychiatry 43:381-440; 1975.

28. Pittendrigh, C. S.; Daan, S. A functional analysis of curcadian pacemakers in nocturnal rodents. IV. Entrainment: Pacemaker as a clock. J. Comp. Physiol. 106:291-331; 1976.

29. Rietveld, W. J.; Hekkens, W.; Groos, G. A. The effect of long term application of clorgyline on the circadian rhythm of food intake in the rat. In: Reinberg, A.; Smolensky, M.; Labreque, G., eds. Annual review of chronopharmacology. vol. 3. Oxford, UK: Pergamon Press; 1986:29-32.

30. Rommelspacher, H.; Bade, P.; Bludau, J.; Strauss, S. Hemmung der Monoaminoxidase und Tag-Nacht-Rhythmus: Korrelation zwischen physiologischen und biochemischen Parametern. Arzneim.-Forsch. 26:1078-1080; 1976.

31. Rosenwasser, A. M.; Adler, N. T. Structure and function in circadian tıming systems: Evidence for multiple coupled circadian oscillators. Neurosci. Behav. Rev. 10:431-448; 1986.

32. Sakurai, E.; Yamasakı, S.; Niwa, H.; Jossan, S. S.; Hallmann, J.; Oreland, L. Relation between serotonin and dopamine uptake rates, transmitter concentrations and monoamine oxidase activities in various regions of the rat brain. Biogenic Amines 7:1-10; 1990.

33. Shibata, S.; Liou, S. Y.; Ueki, S. Different effects of amino acids, acetylcholıne and monoamines on neuronal activity of suprachiasmatic nucleus in rat pups and adults. Neurosci. Lett. 39: 187-192; 1983.

34. Siebert, U.; Wollnik, F. Wheel running activity rhythms in two inbred strains of laboratory rats under different photoperiods. Physiol. Behav. 50:1137-1143; 1991.

35. Sokolove, P. G.; Bushell, W. N. The chi square periodogram: Its utility for analysis of circadian rhythms. J. Theor. Biol. 72:131$160 ; 1978$.

36. Takahashi, Y.; Usui, S.; Honda, Y.; Ebihara, S. Effects of therapeutic drugs for affective disorders on free-running circadian periods of rat behaviors. Chronobiologia 14:247; 1987.

37. Tamarkin, L.; Craig, C. J.; Garrick, N. A.; Wehr, T. A. Effect of clorgyline (a MAO type A inhibitor) on locomotor activity in the syrian hamster. Am. J. Physiol. 245:R215-R221; 1983.

38. Turek, F. W. Effects of stimulated physical activity on the circadian pacemaker of vertebrates. J. Biol. Rhythms 4:135-147; 1989.

39. Van Cauter, E.; Turek, F. W. Depression: A disorder of timekeeping? Perspect. Biol. Med. 29:510-519; 1986.

40. van den Pol, A. N.; Tsujimoto, K. L. Neurotransmitters of the hypothalamic suprachiasmatic nucleus: Immunocytochemical analysis of 25 neuronal antigens. Neuroscience 15:1049-1086; 1985.

41. Wehr, T. A.; Goodwin, F. K. Biological rhythms and psychiatry. In: Arieti, S.; Brodie H. K. H., eds. American handbook of psychiatry. vol. 7. New York: Basic Books; 1981:46-74.

42. Wehr, T. A.; Lewy, A. J.; Wirz-Justice, A.; Craig, C.; Tamarkın, L. Antidepressants and a circadian rhythm phase-advance hypothesis of depression. In: Collu, R.; Ducharme, J. R.; 
Barbeau, A.; Tolis, G., eds. Brain peptides and hormones. New York: Raven Press; 1982:263-276.

43. Wehr, T. A.; Wirz-Justice, A. Circadian rhythm mechanisms in affective illness and in antidepressant drug action. Pharmacopsychiatry 15:31-39; 1982.

44. Welsh, D. K.; Moore-Ede, M. C. Lithium lengthens circadian period in a diurnal primate, Saimiri sciureus. Biol. Psychiatry 28 : $117-126 ; 1990$.

45. Wirz-Justice, A.; Campbell, I. C. Antidepressant drugs can slow or dissociate circadian rhythms. Experientia 38:1301-1309; 1982.

46. Wollnik, F. Strain differences in the pattern and intensity of wheel running activity in laboratory rats. Experientia 47:593-598; 1991.
47. Wollnik, F.; Döhler, K.-D. Effects of adult or perinatal hormonal environment on ultradian rhythms in locomotor activity of laboratory LEW/Ztm rats. Physiol. Behav. 38:229-240; 1986.

48. Wollnik, F.; Gärtner, K.; Büttner, D. Genetic analysis of circadian and ultradian locomotor activity rhythms in laboratory rats. Behav. Genet. 17:167-178; 1987.

49. Wong, D. T.; Bymaster, F. P.; Horng, J. S.; Molloy, B. B. A new selective inhibitor for uptake of serotonin into synaptosomes of rat brain: 3-(p-Trifluoromethylphenoxy)- $N$-methyl-3-phenylpropyl-amine. J. Pharmacol. Exp. Ther. 193:804-811; 1975.

50. Yamada, N.; Shimoda, K.; Ohi, K.; Takahashi, S.; Takahashi, $K$. Free-access to a running wheel shortens the period of freerunning rhythm in blinded rats. Physiol. Behav. 42:87-91; 1988. 